\title{
The Features of Building Integrated Digital Educational Environment for Engineering Education
}

\author{
Sergey A. Slastnikov ${ }^{1 *}$, Denis A. Korolev ${ }^{1}$, and Aleksandr V. Belov ${ }^{1}$ \\ ${ }^{1}$ National Research University Higher School of Economics, Moscow, 123458, Russia
}

\begin{abstract}
The work describes the approaches and technologies applied in building the digital educational environment for training students of engineering courses in MIEM HSE. Such an environment intended to cover all aspects of the educational process for engineers, considering modern tendentiousness of higher education: particularly, academic and project parts, online and offline components of the educational process.
\end{abstract}

\section{Introduction}

Digital technologies are irrevocably changing different scopes of human activity, including the educational areas. Most naturally this process should develop in the universities and departments of mathematical, technical, and engineering sciences. Of course, distinguishing features of the educational processes for each direction should be highlighted separately.

In the past, within training the specialist, the education with specializations on the undergraduate levels $(3+2$ or $3+2,5$ year) was practiced. To a limited extent, specializations changed the specificity of education within the profession but remain lecture-practical lessons, usually with the point on the practice. New training model for training engineers, realized in the number of leading universities, implies basic engineer and professional training in the first two years, developing STEM-competitions (Science Technology Engineering Math), interdisciplinary and high integration of industrial partners in the training process. An important direction of development the collaborations with industrials is the project-education. Moreover, this is the base model for training the engineers in HSE. «The feature of our approach to that model is that we not only held student projects but built the whole educational processes considering requirements of the project» - noted the scientific advisor, an acting director of MIEM HSE Evgenyi Krouk [1].

\section{$2 \quad$ Fundamental training}

Compared with the specialist's training programs, which duration less than 5 years, the interaction time between student and teachers, and total hours allocated to mathematical subjects, for example, in engineers training, significantly reduced. To enhance the training

\footnotetext{
Corresponding author: sslastnikov@ hse.ru
} 
without intensifying the number of hours, the education form should be changed. The apparent areas here is the complementation of the internal studies and self-training with the various online tools with the automation of some processes:

- $\quad$ tasking (generation of versions based on the pattern)

- $\quad$ solutions review

- description of the possible causes of the mistakes

- $\quad$ measuring the results

- $\quad$ detection tendencies for each student

- $\quad$ suggestions for changing the educational trajectory to fill the gaps in previously studied subjects, and also to each the aims, settled by an educational program.

Obviously, with such an approach, the option "to send a student to take an online course" would not solve most of the problems. The more tight integration of the educational environment, teachers' work, and automatic mechanisms, operating above the educational environment was demanded. In particular, the global "digital footprint" monitoring and the assistant system for recommendations.

Thus, a query for developing the integrated informational and educational environment for solving the tasks listed above is formed. At the same time, the application scope is not limited by basic disciplines; that is why the using tools should be sufficiently universal. Nevertheless, the given environment architecture should be open to connecting new tools for solving specific tasks within a particular discipline.

The project of creating the information and educational environment in MIEM HSE called "Solver" as the name of the main feature of the environment. Its full combination includes both usual LMS (learning management systems), using in the higher education institutions, the integration with various administrative services, and the number of specific elements allows to automate the educational content and collect the personalized data on how the educational process is going, making instant decisions about the changes in the student's educational trajectory.

The methodology of education with applying the informational and educational environment suggests the presence in LMS tasks with auto-checking of the solutions. Such testing is implemented in any LMS, while it is about the typical search for the matching or checking the option out of the list. However, for the more specific tasks demanded more specific tools, allows working with, for example, the equations, the diagrams, to process the string answers and analyzing the program code. At the same time, authors are aware of the motivation characteristics of the students, and on the technical level, seek to implement the variations of the tasks itself, which do not cancel more general solutions. The variation of tasks could be implemented by the presence of the previously set versions, which issued randomly, or by personalized auto-generating of those versions in the cases where applicable.

In the successful digitalization of the educational disciplines, the work with the students in the form of the "flipped class" becomes possible. Flipped class means that all basic materials and typical tasks student learns by himself, including the ones in "Solver" with the feedback from it, while more sophisticated cases and problems will be studied on the internal sessions. This way the classes transfer from the narrative form to the discussion.

Indeed, such an approach will demand both creations of a significant amount of digital materials and tangible changes in the way of giving lectures and practical lessons. Discussion about the usefulness of the lectures and their present form in internal training is not considered in the given article. However, the problem does not appear from anywhere and requires the solution, which will be efficiently using the intern session time while we have the widely known online alternatives. Note that by "digitalizing" of the courses, we do not mean the mandatory recording of the video courses, specific to the public online course (POC). Video format undoubtedly crucial in online courses but case of complementation of 
the internal class with the online tools, the priority would be for interactive part ("Solvers" and the online tests for self-control), for the illustrative materials (exercise machines, simulators, links to the additional materials), and the other forms of annexes to the internal sessions.

Note that students are convenient for solving posed tasks. If the task is to pass the course, that does not mean "learning" the course. In passing the online course, the success criteria are to gain a particular score and not the knowledge of the subject and the ability to apply them in the typical and interdisciplinary tasks. We can talk about cheating and technical meanings against it, including intern exams and proctoring online, but it will not solve the problems systematically because it is a try to solve the consequences but not the problem. That is why one of the tasks of the digital educational environment is to build the conditions when cheating is not useful. Students are cheating because between the mark and the usefulness of the knowledge, they mostly choose the mark as the fast material result, and the usefulness of the knowledge sometimes is not apparent. The objective for the institution of higher education is in making the usefulness visible (which was necessary and without digital means) and building such an educational system in which once learned will be using multiply further and inability to apply one or another type of knowledge learned before will be instantly determined. Afterward, it will be suggested to the student to relearn the material. In the current practice, that leads to the transition to fee-based education and other punishments, while using a digital learning environment it just means the increasing volume to the current program.

\section{$3 \quad$ Project model}

In 2017 in the "Skolkovo" innovation center, the event "School of mentors" was held. The event was dedicated to the integration of project-based learning formats in universities. As a result, the compilation [2] was created, in which relevant and fascinating examples of integration the project-based formats in educational programs of 6 Russian universities: Moscow Polytech, Far Eastern Federal University, Southern Federal University, NIU «Higher school of economics,» Ural Federal university - Nizhny Tagil Technical university (branch) and Lobachevsky Nizhny Novgorod State University.

One feature of the project-based educational model is to orient students to selfdetermined activities: individually, in pairs, in groups, which students should do in a specific timeframe. This approach seamlessly blends with the group approach to education. Project-based model suggesting solving the task, considering the using of different methods and meanings of education on the one hand, and on the other - integration of knowledge and skills from several areas of science, technology and engineering, creative abilities, etc. the results of the ended projects should be visible: if it is theoretical problem then they should find its concrete solution if the practical one - the result should be ready to apply [3].

Since 2014 in HSE started the so-called "Project market" [4]. It was founded for providing all the bachelor educational programs with the projects, as they contained the projects as the necessary element of the training, correspondingly to the educational standard. In the 2018/19 school year, in the Tikhonov Moscow Institute of Electronics and Mathematics ("engineering branch" of HSE), the project-based model of education was approved by bachelor's programs of all departments. One feature was the several public stages of presentations and assessments of each project. As an approbation result, in June 2019, MIEM held the Techno-show of the projects, which included 18 most outstanding student's projects [5].

Moreover, how that approach to education affects the building of an integrated digital educational environment? Several vital aspects could be highlighted. On the one side, 
education in the project suggests the outgrowth from the traditional lecture-audit model to build the educational process in the frame of the specific projects. That leads to the necessity of forming for each project their educational track, which in the condition of the limited time and teaching resources possible only based on applying the digital educational means. Thus, we return to the problem of forming individual educational trajectories. On the other side, students' "integrity" within the project potentially is one of the essential characteristics of the future employee. Thus, it is not about the final mark, but about monitoring of the student's work during the project: regularity and quality of the work, the fulfilment of the possessed tasks in time, etc. Considering the stated above, the necessary component of the integrated digital educational environment also sees as an instrument of project management.

\section{$4 \quad$ Digital educational environment}

Different approaches in developing the digital educational environment considering in works [12-14]. We are pointing the attention to the implementation - integration in the training process - both our ideas and existing methodologies. The crucial aspect of the integration of different program systems and components in any informational (program) environment is the problem of integrating the modules between each other. Thus, the standard criteria for the «quality» of integration do not exist.

At the present stage of development, in every higher education institute, there are several functioning information systems and their components interlocked in any way. Producing new technical boundaries in trying to implement and integrate new modules. While designing the whole structure of the digital educational environment, we try to entirely distance from existing (using in the present) information systems. Fig. 1 shows the general structure of the digital educational environment. Briefly describe its components.

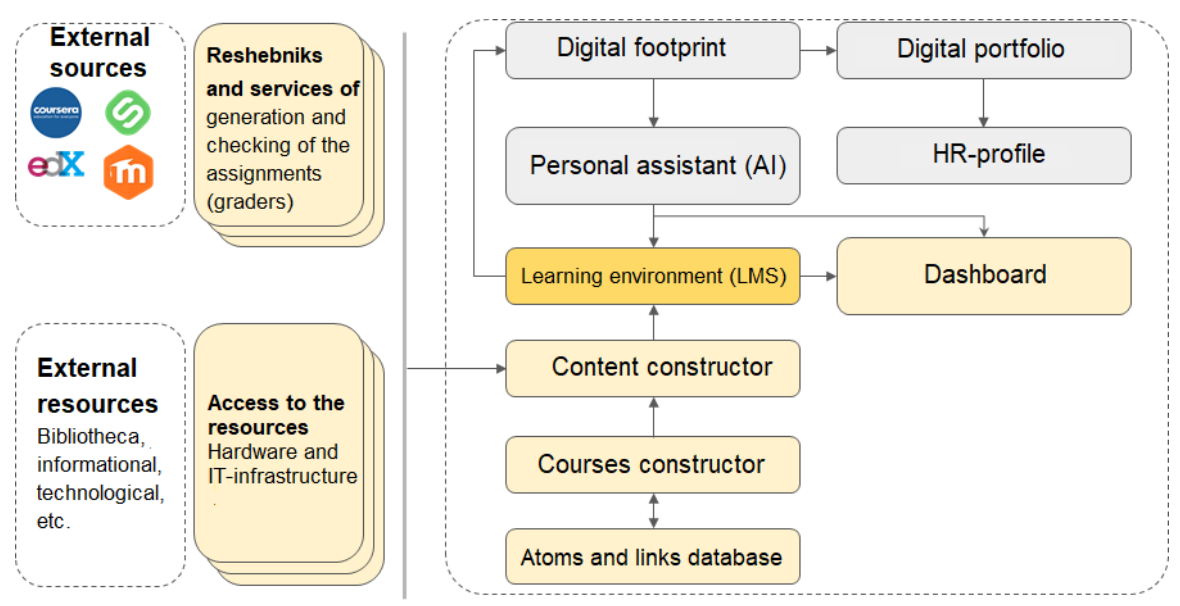

Fig. 1. The general structure of the digital educational environment.

In its center placed LMS - education control system, suggesting containment in its educational, testing, and measurement and other content. There are more than a dozen of LMS-type systems [6], and obviously, it is impossible to choose one indiscriminately. Besides, note that support of the common in the area (industry) standards, particularly the Learning Tools Interoperability standard [7], are strictly required for such systems.

Below there are linearly linked units: «Content constructor», «Course constructor» and «Atoms, and links database». Let us consider them in ascending order. Atoms database 
consists of indivisible parts (atoms) of courses with utilization in levels of difficulty (depth of diving) in the learning unit, which is necessary for presence in higher education institutions entity different training directions from various fields. For example, students of humanitarian professions are also studying math and statistics but on a fundamentally different «immersion level» then the mathematicians who learn engineering subjects but not that deep as the engineers, etc. Atom's example is shown in fig. 2.

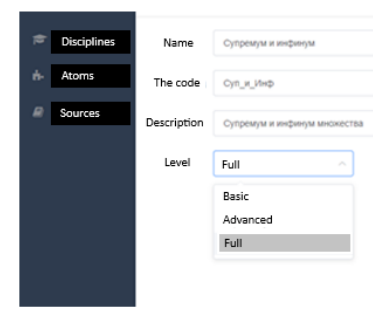

Fig. 2. Atom's example.

Links between atoms determine correlations of «knowledge units.» Thus, the links are not supposed to be in only one discipline; on the contrary - generally, they are interdisciplinary. In the example, in fig.3, there is an atom, based on (linked to) the others, which can be involved in the different courses (in particular, in physics and mathematics).

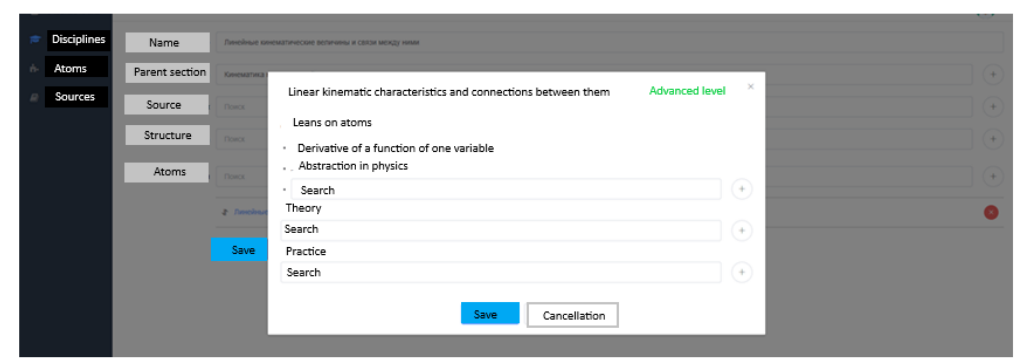

Fig. 3. The example of the links between the atoms.

Courses constructor is an instrument, which allows creating the structure of the courses «brick by brick» based on the atoms. In the given component, it is a question of creating a course structure without content bindings. The simplest course construction case shown in fig. 4 . 


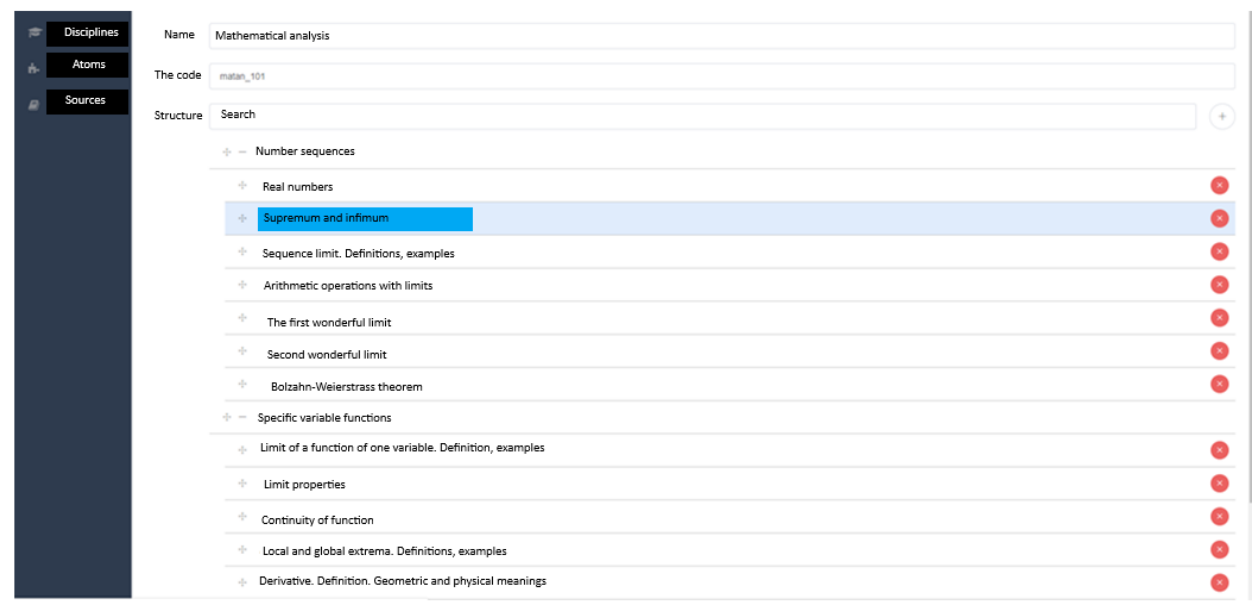

Fig. 4. Course structure example.

The depth of partition nesting levels can be unlimited, but almost all LMS systems have some boundaries.

«Content constructor» creates the content of each section and the whole course. The constructor can be both the part of the LMS system and the tool itself. In particular, the course can be built from the parts (sections) of online platforms (Coursera, Stepik, etc), which supports LTI-standard.

Visualization of the educational trajectory (dashboard) is a tool necessary for every aspect of the educational process. It helps to "get a glimpse of the picture» both for students, teachers and heads of educational programs. The number of works [8-11] is devoted to the importance of that mechanism, including in engineering education. For students, it demonstrates the role of «non-core» (from the student point of view) subjects and its connection to other courses. For professors and the heads of the programs, it allows finding in the educational program disconnected course sections and other inconsistencies in the structure of given disciplines. "Atoms and links constructor» and «Courses constructor» are the data source for visualization (fig. 5).

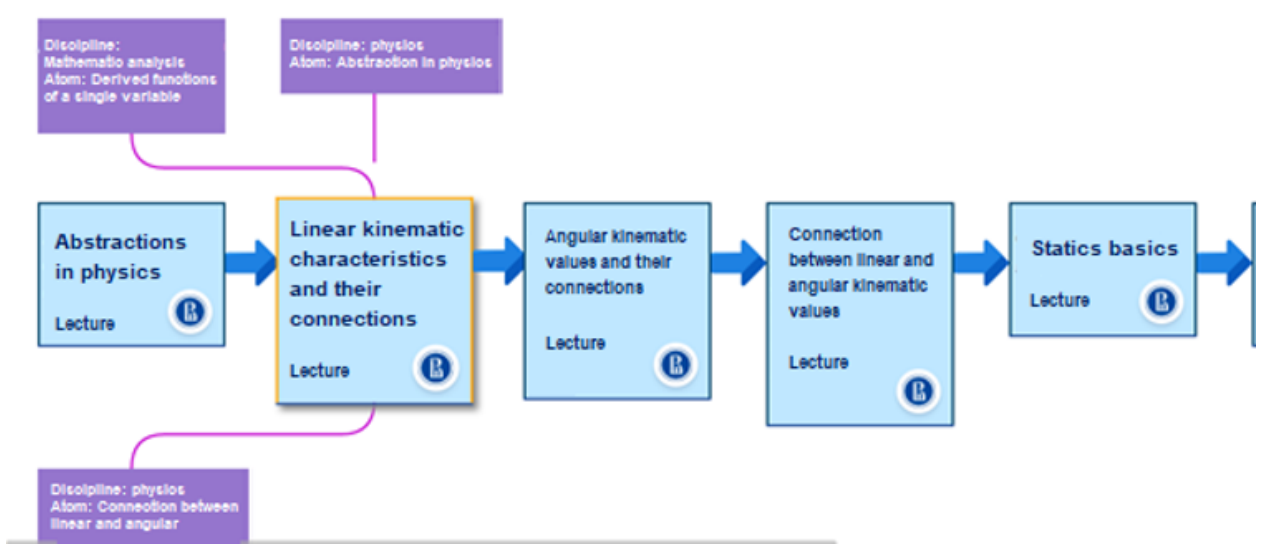

Fig. 5. Visualization of the students educational trajectory.

A personal assistant is a tool capable of determining student's strengths and weaknesses and recommending to them sections of the different courses for review or advanced 
learning in a given area (not necessary in one discipline frame). Naturally, such mechanisms are based on AI technologies [21-22].

«Digital footprint» modules [15-17] and «Digital portfolio» [18-20] can be considered as the tools to motivate students. Student's digital footprint refers to the whole educational track in training process: quality and efficiency in solving the intermediate tasks, following timeframes, video records of defense of all kinds of projects, etc. based on those data forming digital portfolio of a graduate student, which can give to the employer «visual representation» about the person and their reputation.

\section{$5 \quad$ Conclusions}

As the results of the work, let us point to the main features of using a given digital environment for the participant of the educational process.

For the students, there can be highlighted the following essential aspects:

- transparency of the educational plan, clarity of the objectives and current tasks;

- $\quad$ accounting of the achievements and fails, reputation accumulation;

- $\quad$ individual approach in education, adaptive educational trajectories;

- $\quad$ access to all of the educational materials.

For the teachers, the educational environment allows:

- to minimize routine in preparation of repeated courses;

- to receive objective feedback on the course and detailed diagnostic of each student' actions;

- to have the process a clear picture of the activity and achievements of each student.

For making strategy and management decisions, the supervisors of educational programs will be provided with a larger amount of data. To which can be referred:

- clarity of content of all the courses, the possibility for regular expertise of relevance and level of content;

- alignment of the educational program in general;

- data for early determination of underachievement students;

- objective data for solving conflicts.

\section{References}

1. Engineering education of the future: the transformation of Russian institutes https://www.5top100.ru/news/108595/

2. L.A. Evstraeva, N.V. Isaeva, O.V. Leshukov, Proectnoe obychenie, Practiki vnedreniya $\mathrm{v}$ universitetach, [Project-based education. Practices for integration to universities] Moscow (2018)

3. T. Grebenuk, O. Grebenuk, Uchebnik I practicum dlya academicheskogo bacalavriata, [Education theory. Manual for academicals bachelors] ed. 2nd edition, rev., Litres Publ (2018)

4. Yarmarka proektov NIU VSHE [HSE Projects Fair]. https://pf.hse.ru/

5. MIEM tech-cup: from studies to patents. https://www.hse.ru/news/edu/284031998.html

6. LMS systems review. https://elearningindustry.com/review-learning-managementsystem-lms

7. Learning tools interoperability. http://www.imsglobal.org/activity/learning-toolsinteroperability 
8. V.V. Gamukin, Individual educational tracks in higher education institutions, Engineer education, 25, pp. 27-36 (2019)

9. N.V. Karamzina, E.N. Fedorova, G.M. Yanushkina, The features of student realization of individual educational tracks, Modern problems of science and education, (3), pp. 297-297 (2014)

10. S.M. Kaplunovich, The possibilities to build student's educational track in conditions of realization the technology of adaptive education in nearest development zone, International journal of innovative education, (9), pp. 50-55 (2017)

11. K. Sharifzyanova, J. Shtreter, R. Nauryzbayeva, Structural-Functional Model of Designing Individual Educational Path of Teacher's Professional Development in Conditions of Information Educational Environment, International Journal of Environmental \& Science Education, 10(4), pp. 523-532 (2015)

12. E. V. Rumyantsev, A.U. Matrochin, S.S. Mishurov, K.E. Romanova, The conception of digitalizing the educational environment of engineers in globalization conditions, Engineering education, 25, pp. 56-64 (2019)

13. N.V. Molotkova, E.A. Rakitina, A.I. Popov, The mechanism of using the digital educational environment in engineers training, The problems of modern practice, 2 (68), pp. 163-172 (2018)

14. O.V. Natal'ia, V.V. Glukhov, Basics of organization educational system in professional training in digital economics conditions, St. Petersburg State Polytechnical University Journal, Economics, 11(2), p. 7 (2018)

15. Y. Sürmelioğlu, S.S. Seferoğlu, An examination of digital footprint awareness and digital experiences of higher education students, World Journal on Educational Technology: Current Issues, 11(1), pp. 48-64 (2019)

16. V. Benson, F. Filippaios, Effects of a digital footprint on career management: evidence from social media in business education, World Summit on Knowledge Society, pp. 480-486, Springer, September 2010, Berlin, Heidelberg (2010)

17. A.L. Fursov, New methods in staff selection: main characteristics of employees' "digital footprint", Relevant problems of socio-humanitarian sciences and education: essences, conceptions, prospective, pp. 1057-1062 (2019)

18. A. Zasobiva, L. Kuklina, Part-time student's digital portfolio, Russian higher education, 7 (2007)

19. K.V. Rochev, G.V. Korshunov, Formation of a graduate's digital portfolio based on interaction with employers' to create a competitive environment for students and increase their activities, Educational technologies and society, 19(2) (2016_

20. S.A. Djanibilova, The structure of student's digital portfolio, Information and education: communication borders, 10, pp. 14-15 (2018)

21. I.A. Kostromin, Virtual digital assistants, BBK 65.04 K64 Publ. Responsible: Ph.D. in economics, rector of Ural State Economical University, p. 199 (2017)

22. E.V. Soboleva, N.V. Shalaginova, Virtual assistant in the determination of intellectual competence for training specialists of future professions, A person in culture and education: psychological assistance, p. 526 (2018) 